Im Gegensatz dazu begreift der zweite Lösungsvorschlag auf der Suche nach dem Ich das Ich (den menschlichen Charakter, die menschliche Natur) als instabile, sich verändernde Form, was am besten in den Essais (1580-1588) von Michel de Montaigne (1533-1592), dem wichtigsten Vertreter dieser Auffassung, zum Ausdruck kommt. Durch die Methode der Selbstbeobachtung hat er in seinen Essais gezeigt, dass die Erkundung des Ich nie abgeschlossen ist. Durch seine wandelbare Form hat der Mensch somit auch die Möglichkeit, sein Ich, seinen Charakter und sein Verhalten zu verändern, was eine grundlegende Beobachtung mit Bezug auf die proklamierte Besserungsintention der Moralischen Wochenschriften darstellt. Denn würden die spectatorialen Produzent*innen von einem statischen Ich ausgehen, wäre der belehrende Aspekt des ,prodesse“ darin hinfällig. In der Essay-Form (die ebenfalls in den einzelnen Nummern der moralischen Periodika vorkommt) als Ausdruck der Unabgeschlossenheit spiegelt sich zudem die Bewegung wider, mit der das Ich erkundet wird. Als literarische Ausdrucksform eignet sich neben dem Essay die Maxime, denn ,[f]ür sich genommen bietet eine Maxime immer nur eine partielle, unvollständige, nicht beendete, nicht vollendete Beschreibung der Form des Ich. Sie ist strukturell und semantisch autonom und sich selbst genügend“ (Van Delft 2005a, 15). Die analytische Vorgangsweise folgt dem Modell der Anatomie: Wie beim Sezieren eines Organismus arbeitet sich der/die Moralist*in Stück für Stück ins Innere des Menschen vor, zum Kern des Ich: ${ }^{55}$ „Von Montaigne bis Marivaux (und sogar noch darüber hinaus) hat dieses Modell den Blick der Beobachter bestimmt, die die Form des Ich genauer ,belauern' (wie es in den Essais heißt), indem sie bis zu den innersten und geheimsten Schichten , vordringen“ wollen [kursiv im Orig.]“ (ibid., 16-17).

\title{
1.5 ZUSAMMENFASSUNG
}

Alle in diesem Abschnitt genannten Gattungsmerkmale (i. e. periodische Erscheinung, Übersetzungen/Nachahmungen/Adaptationen, weibliches Lesepublikum, fiktive Produzent*innen, Soziabilität, vielfältige literarische Formen und Gattungen sowie Menschenbeobachtung) sind in den französisch- und spanischsprachigen Moralischen Wochenschriften in unterschiedlichen Ausmaßen anzutreffen. Im Zuge der Wissens- und Welterzeugung des neu entstehenden bürgerlichen Lesepublikums spielt vor allem die Menschenbeobachtung eine eminente Rolle, zielen die Produzent*innen doch auf die (moralische) Besserung ihrer Leser*innenschaft ab. Dazu genügt es allerdings nicht, die ideale Welt mit ihren erwünschten (geschlechtsspezifischen) Werten, Normen und Praktiken nur zu präsentieren, denn das Publikum muss erst darin geschult werden, die Unterschiede zwischen dem gegenwärtigen Ist-Zustand und dem angestrebten SollZustand wahrzunehmen, um in weiterer Folge sich selbst und Andere in diesen SollZustand zu versetzen.

Primär muss auch noch die Neugier des Publikums, die Montaigne als Bestandteil der widersprüchlichen menschlichen Natur (und somit als anthropologische Konstan-

55 Zur Entwicklung des Fokus auf das Beobachten der Sitten, das stark mit dem anthropologischen/anatomischen Beobachten des Körpers einhergeht, siehe Louis van Delft (2005b) Les spectateurs de la vie. Généalogie du regard moraliste. 
te) ansieht, an den Inhalten der Wochenschriften geschürt werden; das heißt, das Publikum muss motiviert werden, die Zeitschriften in (un-)regelmäßigen Abständen (zu kaufen und) zu lesen. Um das Interesse der Leser*innen an der spectatorialen Welt und ihrem Wissensschatz - auch bei mehrmaliger Lektüre - immer wieder aufs Neue zu wecken, greifen die Wochenschriftenproduzent*innen beständig auf Erzählungen zurück, mit denen die Emotionen der Leser*innen derart gelenkt werden, dass ihre Neugier teilweise gestillt, teilweise neu entfacht wird (cf. Lodge 1992, 13-16).

Abgesehen davon sind Erzählungen wesentlich an der Produktion, Speicherung und Kommunikation des soziokulturell geteilten Wissensschatzes beteiligt. Da es letztlich aufgrund der hohen Komplexität und großen Diversität der alltäglichen Wirklichkeit unmöglich ist, alles um uns herum in seiner Gänze zu erfassen, erleichtern vorgefertigte Bilder, sogenannte Stereotype, die Wirklichkeitswahrnehmung. Im Folgenden werden narrative Diskurse, Medien und Stereotype als drei Komponenten, die im Konstruktionsprozess von Wissen und Weltbildern für Gesellschaften eine tragende Rolle spielen und Modi des Zugangs zur Wirklichkeit darstellen, näher beleuchtet und für die vorliegende Studie fruchtbar gemacht. 
